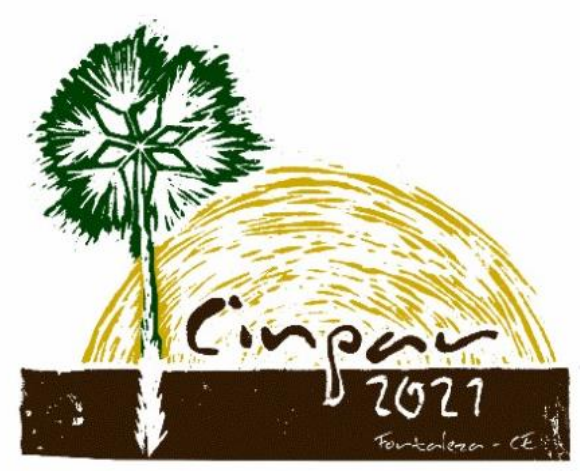

XVII Congresso Internacional sobre Patologia e

Reabilitação das Construções

XVII Congreso Internacional sobre Patología y Rehabilitación de las Construcciones

XVII International Conference on Pathology and Constructions Rehabilitation

FORTALEZA (Brasil), 3 a 5 de junho de 2021

https://doi.org/10.4322/CINPAR.2021.037

\title{
Impacto das intervenções dos usuários no estado de conservação e desempenho de um edifício modernista
}

\section{Impact of users interventions on the state of conservation and performance of a modernist building}

\author{
Tatiana Renata Pereira JUCÁ ${ }^{1}$, Lara Monalisa Alves dos SANTOS², Catarina Moraes de Oliveira \\ SOMBRIO ${ }^{3}$, Janes Cleiton Alves de OLIVEIRA ${ }^{4}$, Vanda Alice Garcia ZANONI ${ }^{5}$ \\ ${ }^{1}$ Pontifícia Universidade Católica de Goiás, Goiás, Brasil, centraldedesempenho@gmail.com \\ ${ }^{2}$ Universidade de Brasília, Distrito Federal, laramonalisa.arquitetura@gmai.com \\ ${ }^{3}$ Universidade de Brasília, Distrito Federal, Brasil, csombrio@gmail.com \\ ${ }^{4}$ Universidade Federal de Goiás, Goiás, Brasil, janescleiton@ufg.br \\ ${ }^{5}$ Universidade de Brasília, Distrito Federal, Brasil, vandazanoni@unb.br
}

Resumo: As intervenções realizadas pelos usuários ao longo da vida útil das edificações podem impactar o estado de conservação e o desempenho dos sistemas construtivos, se não forem geridas de forma adequada. Após 60 anos da sua construção, alguns edifícios modernistas que integram o conjunto arquitetônico da Esplanada dos Ministérios em Brasília, capital federal do Brasil, encontram-se em situação de obsolescência funcional, no seu todo ou em partes de seus sistemas. Nessa condição, readequações e necessidades de atualização são requeridas para que os edifícios continuem exercendo suas funções com desempenho satisfatório, sem descaracterizar a sua feição. Sendo assim, o objetivo deste artigo é avaliar o impacto das adaptações ao uso efetuadas em um dos edifícios dos Ministérios, atualmente em desuso. A coleta de dados se deu por meio de levantamento documental e inspeção predial, tal como preconizada pela ABNT NBR 16747: 2020. Os resultados apontaram que os principais impactos ocorreram na envoltória do edifício para atualização dos sistemas prediais e intervenções para melhorar o conforto térmico. Conclui-se que as inadequações das intervenções ao longo da vida útil afetaram os elementos da envoltória e requerem ação imediata de seus gestores para impedir situações de risco aos usuários e transeuntes. Principalmente, ações de manutenção predial planejadas são demandas necessárias para conservar as características estéticas, integridade e valores culturais do edifício.

Palavras-chave: Desempenho; obsolescência funcional; intervenções dos usuários, manifestações patológicas, patrimônio moderno.

Abstract: The interventions carried out by users throughout the useful life of buildings can impact the state of conservation and the performance of constructive systems, if not properly managed. After 60 years of its construction, some modernist buildings that make up the architectural ensemble of the Esplanada dos Ministérios in Brasília, the federal capital of Brazil, are in functional obsolescence, in whole or in parts of their systems. In this condition, readjustments and updating needs are required for the buildings to continue exercising their performance functions, without detracting from their features. Therefore, the purpose of this article is to assess the impact of adaptations to use made in one of the Ministries' buildings, currently in disuse. Data collection took place through documentary survey and building inspection, as recommended by ABNT NBR 16747: 
2020. The results showed that the main impacts occurred on the building envelope to update building systems and adaptations to improve thermal comfort. It is concluded that the inadequacies of interventions throughout the useful life affected the elements of the envelope and require immediate action by its managers to prevent risk situations for users and passers-by. Mainly, planned building maintenance actions are necessary demands to preserve the building's aesthetic characteristics, integrity and cultural values.

Keywords: Performance; functional obsolescence; users' interventions, pathological manifestations; modern heritage.

\section{Introdução}

Edificações públicas com funções administrativas precisam ter flexibilidade e adaptabilidade de usos, pois são comuns as trocas dos órgãos administrativos que ocupam esses espaços edificados. Além de se adequar aos diferentes usos e públicos, devem permitir as atualizações tecnológicas dos sistemas prediais e precisam ser duráveis em sua estrutura e materiais constituintes, porque os recursos disponíveis nem sempre são suficientes para a manutenção programada.

Braga e Paiva (2016) avaliam que a flexibilidade dos espaços é uma das características mais relevantes para a permanência dessas edificações no tempo. Ocorre que a flexibilidade dos espaços está relacionada à adaptação funcional, que significa mais do que apenas reorganização de layout e adaptação de novas funções, mas também a receptibilidade a novos sistemas, como os de segurança, informação, telecomunicações, eficiência energética e conforto térmico, por exemplo. No entanto, essas adaptações precisam ser planejadas de maneira a garantir que os demais sistemas funcionem adequadamente, sem gerar danos ou consequências desagradáveis aos usuários ou que comprometam a segurança dos sistemas.

As dificuldades inerentes às ações de conservação de uma edificação, na maioria das vezes, não são consideradas na fase de projeto e, mesmo que tenham sido projetados para alcançar o máximo da sua vida útil, os sistemas sofrem degradação (BOTTEGA et. al, 2020). Quando a edificação tem características que dificultam sua atualização, por impossibilidade técnica ou custo muito elevado, ela corre o risco de ficar obsoleta mesmo sem apresentar degradação do material. John e Sato (2006) salientam que a obsolescência funcional ocorre quando a construção já não cumpre sua função por mudanças das necessidades dos usuários, sejam culturais, tecnológicas, econômicas ou sociais, ameaçando sua vida útil.

De acordo com a NBR 15575 (ABNT, 2013), a durabilidade é um requisito essencial visto que confere a capacidade da edificação ou de seus sistemas de desempenhar suas funções ao longo do tempo e sob condições de uso e manutenção. Desta forma, o diagnóstico das manifestações patológicas presentes nos sistemas é importante para subsidiar decisões que influenciam diretamente no seu desempenho, quando os gestores o usam como ferramenta para corrigir e monitorar os problemas identificados.

Uma tendência indicada por Perez, Tah e Mosavi (2019) é o uso de redes neurais convolucionais (CNN) para uma detecção e localização automatizada de defeitos de construção em vez dos métodos tradicionais de inspeção predial, no entanto ainda há limitações do modelo para aplicações em situações reais e os estudos continuam para que os modelos sejam validados. Outra abordagem proposta por Pereira, Brito e Silvestre (2020) é a necessidade de sistematizar e homogeneizar listas de classificação de elementos construtivos e técnicas de reabilitação, de forma a fornecer uma visão abrangente e relevante dos procedimentos que podem ser utilizados nas ações de diagnóstico e reparo, compondo assim uma ferramenta padronizada para um sistema de inspeção global. 
No Brasil, a ferramenta normativa para inspeção predial, a NBR 16747 (ABNT, 2020), visa avaliar as condições técnicas de uso e operação, manutenção e funcionalidade da edificação e de seus sistemas e subsistemas construtivos, de forma sistemática e predominantemente sensorial. Por meio desta, ocorre a identificação das manifestações patológicas, que se dá pelo funcionamento inadequado, sintomas ou sinais aparentes de degradação, ou que somente possam ser identificados por ensaios específicos.

Neste contexto, o objetivo deste artigo é avaliar o estado de conservação e os danos decorrentes das adaptações ao uso efetuadas pelos usuários na envoltória do Bloco 0 , edifício que compõe o conjunto de edificações da administração pública federal da Esplanada dos Ministérios (Figura 1), na capital do Brasil, Brasília - DF. Projetado por Oscar Niemeyer, o edifício em análise é um exemplar do período modernista inaugurado na década de 1960, quando os conceitos de durabilidade, vida útil e desempenho não eram tratados na fase de projeto e execução.

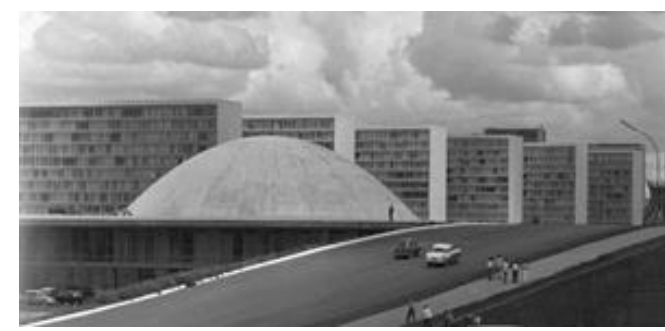

Figura 1 - Fachadas dos Edifícios Públicos da Esplanada dos Ministérios a época da inauguração, 1960. Fonte: Arquivo público do DF.

O Bloco O na Esplanada dos Ministérios atualmente encontra-se desocupado e em espera por uma reforma para adequação e reuso, apresenta degradação de alguns de seus componentes e encontrase em situação de obsolescência funcional em partes de seus sistemas. Justifica-se assim a contribuição deste estudo, considerando que o edifício se localiza no Eixo Monumental da cidade que é um Patrimônio da Humanidade.

\section{Método}

Esta pesquisa caracteriza-se como exploratória, visando ampliar o conhecimento quanto à ocorrência de danos nos sistemas prediais em um edifício em fase de obsolescência funcional. $O$ método adotado para cumprimento dos objetivos propostos foi a inspeção predial por meio de vistoria visual, de forma sistemática e predominantemente sensorial, e análise qualitativa para avaliação dos danos causados pelas intervenções ao uso no estado de conservação dos elementos e sistemas que compõem o edifício.

A coleta de dados para avaliação do estado de conservação dos elementos e sistemas construtivos do edifício seguiu as diretrizes das NBR 16747 (ABNT, 2020) que prevê duas etapas: análise da documentação existente sobre o edifício e a inspeção in loco. Para a análise documental foi solicitada à administração local os projetos existentes, plano e registros de manutenção. Já a inspeção predial se deu por análise sensorial e abrangeu apenas a parte visível do edifício - os sistemas prediais relacionados à envoltória de um edifício. Foi realizado o registro fotográfico dos danos identificados e das intervenções realizadas ao longo dos anos.

Os dados coletados foram analisados e os resultados sistematizados e organizados, relacionando os principais problemas encontrados na envoltória do edifício devido às intervenções dos usuários. São apresentadas onze situações em que as interferências afetaram o desempenho dos sistemas, com imagens ilustrativas, identificação do elemento e da intervenção, assim como os danos e suas prováveis causas. Para efeito desta pesquisa, considera-se que dano é a consequência das manifestações patológicas identificadas. Os elementos objeto de análise são: cobertura, fachadas cegas, fachadas-cortinas e escadas de emergência. 


\section{Resultados e discussões}

O edifício localizado na Esplanada dos Ministérios em Brasília - DF, com 60 anos de uso, possui duas fachadas inteiramente de aço e vidro - do tipo fachada-cortina, voltadas para as orientações leste e oeste. Na fachada oeste há componentes metálicos verticais de proteção solar na cor verde fixados externamente à fachada-cortina atuando como brises. Na fachada leste, os mesmos componentes foram fixados internamente, atuando como persianas. As fachadas laterais (empenas) norte e sul são cegas, revestidas de cerâmica na cor gelo.

Foi possível identificar durante a inspeção predial que, além dos problemas causados pelo envelhecimento dos componentes e exposição às ações impostas, existem intervenções executadas pelos usuários para a adaptação aos novos sistemas de comunicação, climatização e sombreamento. Essas intervenções provocam danos à envoltória do edifício, e se juntam aos problemas relacionados à manutenção, acelerando o processo de obsolescência e prejudicando a habitabilidade, influenciando negativamente na continuidade das atividades no local.

Nos Quadros enumerados de 1 a 4 são apresentadas as onze situações encontradas - quando as interferências afetaram o desempenho dos sistemas.

\begin{tabular}{|c|c|c|c|}
\hline \multicolumn{4}{|c|}{ Quadro 1 - Intervenção realizada no Sistema de Cobertura } \\
\hline Elemento & Intervenção & Dano & Prováveis causas \\
\hline & $\begin{array}{c}\text { Inserção de mãos-francesas } \\
\text { para instalação e suporte } \\
\text { das unidades } \\
\text { condensadoras }\end{array}$ & $\begin{array}{l}\text { Infiltração } \\
\text { de água da } \\
\text { chuva }\end{array}$ & $\begin{array}{c}\text { Perfuração da impermeabilização } \\
\text { nos pontos de passagem e na } \\
\text { fixação dos equipamentos e } \\
\text { dispositivos }\end{array}$ \\
\hline $\begin{array}{l}\text { Figura } 02- \\
\text { Laje de cobertura }\end{array}$ & $\begin{array}{c}\text { Furação da laje para } \\
\text { passagem de tubulação }\end{array}$ & $\begin{array}{l}\text { Infiltração } \\
\text { de água da } \\
\text { chuva }\end{array}$ & $\begin{array}{l}\text { Perfuração da impermeabilização } \\
\text { nos pontos de passagem da } \\
\text { tubulação de drenagem do ar- } \\
\text { condicionado e da antena }\end{array}$ \\
\hline
\end{tabular}

O sistema de cobertura, indicado na Figura 02, sofreu interferências para a fixação das mãosfrancesas usadas de suporte para as unidades condensadoras de ar-condicionado e passagem da rede de drenagem deste. Além disso, também foram instaladas antenas na laje de cobertura onde se nota que a manta impermeabilizante foi perfurada tanto pela antena, quanto pelas mãos-francesas e dispositivos de drenagem. Como consequência, ocorreu a percolação de água para o pavimento inferior, pelas furações que permitiram a sua passagem. Isso afeta as condições de habitabilidade dos espaços que ficam comprometidos pela infiltração da água da chuva, provocando umidade e a formação de bolor.

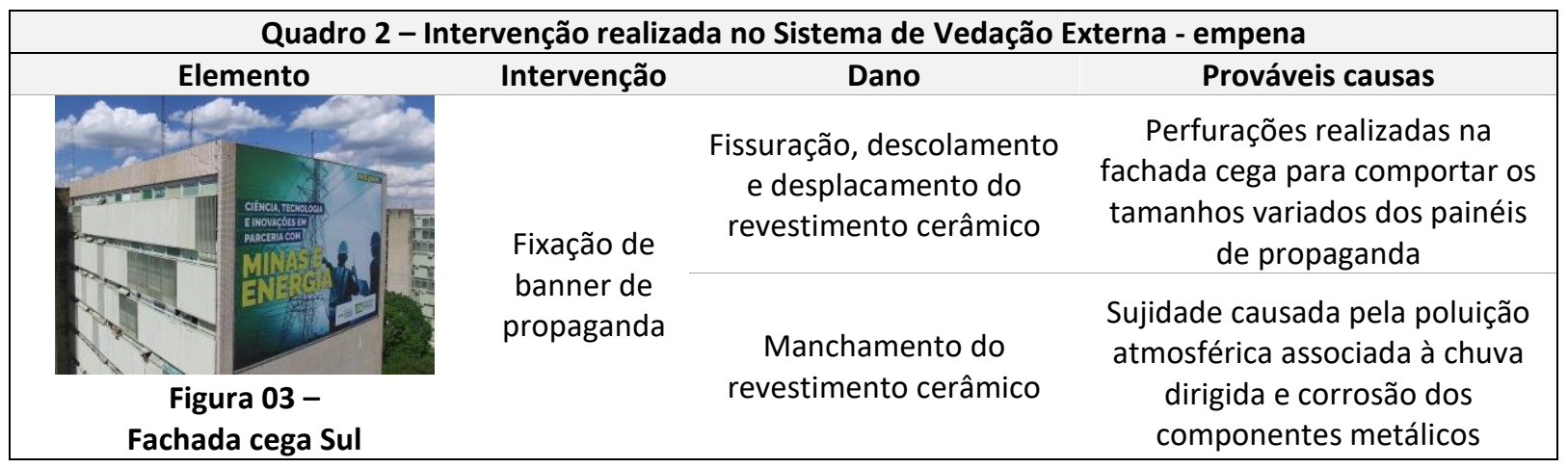

Na Figura 03, observa-se a instalação de um banner de propaganda na fachada cega revestida por placas cerâmicas, que é periodicamente substituído em função das campanhas governamentais. As operações para a fixação e remoção dos banners geram fissuras e descolamentos do revestimento cerâmico, devido à vibração causada pela furação. Caso ocorra o desplacamento das placas 
cerâmicas que estão descoladas, há risco de ferir as pessoas que passam pela calçada. Além disso, os banners causam manchas provocadas pela corrosão dos seus componentes metálicos e pela sujidade resultante do lavado diferenciado da superfície da fachada exposta à poluição e chuva dirigida.

\begin{tabular}{|c|c|c|c|}
\hline \multicolumn{4}{|c|}{ Quadro 3 - Intervenção realizada no Sistema de Vedação Externa - acréscimo } \\
\hline Elemento & Intervenção & Dano & Prováveis causas \\
\hline$=$ & \multirow{3}{*}{$\begin{array}{l}\text { Construção de } \\
\text { escadas de } \\
\text { emergência em } \\
\text { concreto } \\
\text { aparente }\end{array}$} & $\begin{array}{l}\text { Infiltração de água } \\
\text { pela laje de cobertura } \\
\text { das escadas }\end{array}$ & $\begin{array}{l}\text { Falta de manutenção da } \\
\text { impermeabilização }\end{array}$ \\
\hline 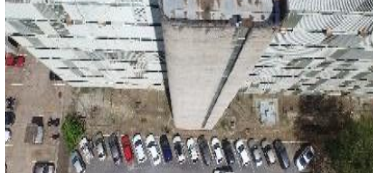 & & $\begin{array}{l}\text { Infiltração de água } \\
\text { pelas fissuras } \\
\text { existentes nas paredes } \\
\text { de concreto }\end{array}$ & $\begin{array}{c}\text { Retração do concreto e } \\
\text { movimentações higrotérmicas }\end{array}$ \\
\hline $\begin{array}{c}\text { Figura } 04 \text { - Escada de } \\
\text { emergência }\end{array}$ & & $\begin{array}{l}\text { Infiltração de água no } \\
\text { encontro da parede de } \\
\text { concreto com a } \\
\text { fachada-cortina }\end{array}$ & $\begin{array}{l}\text { Acabamento ineficiente na } \\
\text { interface da fachada-cortina e } \\
\text { as paredes da caixa de escada }\end{array}$ \\
\hline
\end{tabular}

A construção de uma nova torre em concreto armado aparente (Figura 04) para a inclusão de duas escadas de emergência foi a maior intervenção executada na edificação desde a sua inauguração, visando atender as novas normas de segurança contra incêndio estabelecidas pela NBR 9077. Essa norma versa sobre saídas de emergências de edifícios e sofreu várias atualizações desde 1985 . Na parte superior da torre, a laje de cobertura apresenta-se com o sistema de impermeabilização degradado, o que permite a percolação de água da chuva que desce pela escada, causando lixiviação nos elementos de concreto e formação de bolor em seu interior.

Destacam-se as fissuras horizontais que se apresentam nas paredes de envoltória da caixa das escadas, por onde há percolação de água para o interior. Isto pode ter sido causado durante a concretagem em razão do tratamento ineficaz das juntas de concretagem, bem como pela retração por secagem do concreto em macroambiente quente, ventilado e de baixa umidade típico da capital (gradientes térmicos), agravado pelas dificuldades de execução eficaz de cura úmida de elementos predominantemente verticais.

Para a construção da torre das escadas, a fachada-cortina precisou ser interrompida para permitir a conexão entre o edifício e a caixa de escadas. Por ausência de tratamento da junta, no encontro entre as paredes de concreto da torre e a fachada-cortina existem frestas que permitem a percolação de água da chuva para o interior dos ambientes contíguos às escadas, ocasionando a degradação dos componentes em contato com ela, como por exemplo, os pisos de parquet, forro de gesso e pintura das paredes.

Na face interna do Sistema de Vedação Externa, mostrado na Figura 5, ocorreu primeiramente a retirada das persianas de alumínio, já que as aletas móveis para controle de iluminação e ventilação natural dificultavam o acesso aos puxadores das bandeiras superiores. Porém, como os vidros translúcidos podem gerar ofuscamento nos colaboradores e permitir a passagem da radiação solar para o interior, foi então realizada a aplicação de película fotoprotetora. No entanto, a aplicação inadequada ocasionou bolhas que gera desconforto visual ao olhar para fora do edifício.

Outra intervenção realizada, também indicada na Figura 5, foi a pintura das bandeiras inferiores de branco. A pintura foi realizada com tinta acrílica diretamente sobre o vidro. Esta ação gerou bolhas no acabamento e descascamento da película já que a superfície do vidro é lisa. Diferente do vidro liso, o vidro pintado absorve mais sujidade do ambiente e fica com manchas no acabamento. 


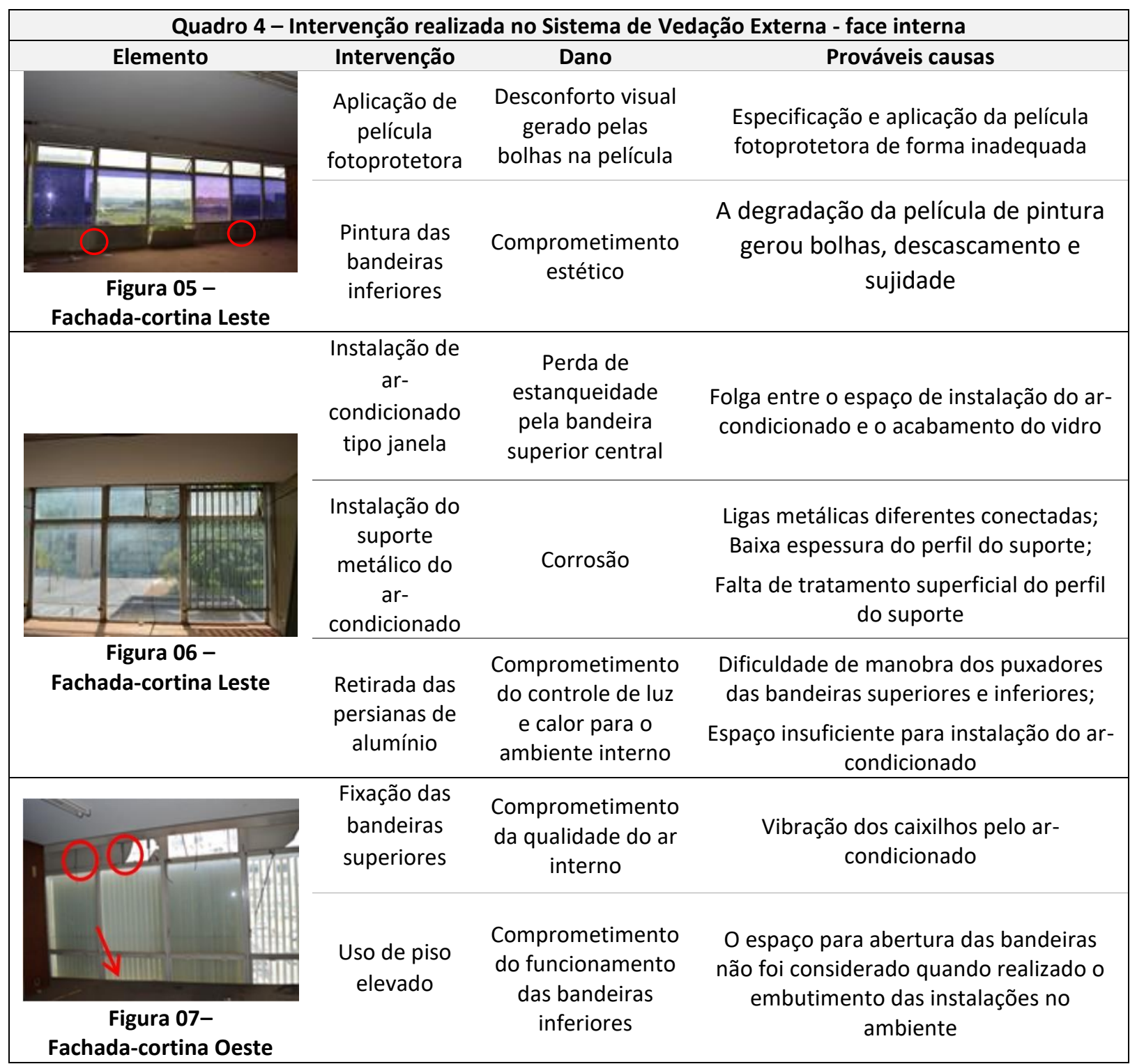

As intervenções indicadas na Figura 6 objetivavam a instalação do ar-condicionado. Para isso, foi necessário ajustar o vidro da bandeira superior que teve seu puxador removido, tornando a folha fixa. Também, foi necessária a soldagem de um suporte para o ar-condicionado que gerou corrosão galvânica, ocasionada pelo contato de liga de aço diferente daquela que compõe a travessa da fachada-cortina, ou pela espessura do perfil do suporte ser inferior à da travessa ou mesmo pela falta de tratamento superficial anticorrosivo deste.

No caso da instalação do ar-condicionado tipo janela (Figura 6), o quadro da bandeira superior onde foi instalado o equipamento é maior que o necessário, por isso foi necessário ajuste no vidro. A existência de folgas para encaixe do equipamento permite a percolação de água para o ambiente interno e, atualmente, todos os ambientes onde havia ar-condicionado que foram removidos estão sem nenhuma proteção, permitindo acesso direto de água da chuva, levando à degradação de pisos e forros de gesso. Além disso, como não havia espaço suficiente para a instalação do arcondicionado (Figura 6), a intervenção realizada foi a retirada das persianas de alumínio. A falta das aletas móveis para controle de iluminação natural pode gerar ofuscamento nos colaboradores e permitir a incidência da radiação solar para o ambiente edificado.

O ambiente indicado na Figura 07 é um auditório em que foi usado um piso elevado em todo o perímetro, até alcançar a fachada-cortina, o que impede a abertura da bandeira inferior; responsável 
pela entrada de ar na ventilação cruzada. Da mesma forma, pode-se observar a instalação de perfis metálicos, travando a abertura das bandeiras superiores, responsáveis pela saída do ar quente para renovação de ar do ambiente. As bandeiras superiores foram fixadas por solda para reduzir a vibração e ruído ocasionados pelo equipamento de ar-condicionado que ficava fixado na laje superior, impedindo assim sua abertura. Na parte inferior, o piso elevado impede o funcionamento das bandeiras inferiores.

Analisando os danos pontuados que, à exceção da instalação de antenas na cobertura, do banner e da construção da escada de emergência, a maior parte das intervenções realizadas visava melhoria do conforto térmico e controle da iluminação natural no interior do edifício. Estas intervenções são demandas relacionadas, em grande parte, à falta de um projeto de atualização da edificação (retrofit) com relação aos sistemas de climatização, conforto visual e térmico do usuário. Isso aponta para necessidades ou para possibilidades tecnológicas diferenciadas das que foram consideradas na época do projeto, seja por mudanças relacionadas às exigências do usuário quanto ao conforto ambiental, seja por avanços tecnológicos dos sistemas.

No que tange à análise documental, cumpre destacar que na época de seu projeto e construção a documentação técnica não contemplava a exigência de manuais e planos de manutenção. As ações de manutenção corretiva, realizadas conforme o surgimento das manifestações patológicas, tampouco atendiam aos requisitos e critérios de desempenho para evitar sua obsolescência. A falta dessa visão integrada entre elaboração de projeto, manutenção e atualização dos sistemas levou a algumas intervenções inadequadas. Por exemplo, os reparos e solução dos problemas, sem um planejamento que abrangesse todas as interfaces entre os sistemas construtivos, afetou diretamente aqueles que compõem a envoltória do edifício.

A documentação fornecida sobre a edificação foi um laudo de inspeção realizado em 2013, o projeto de reforma do prédio realizado em 2015 , o edital de licitação da obra também do mesmo ano e um documento que embasa o pedido de retrofit. O laudo de inspeção foi realizado pelo Ministério do Planejamento, Orçamento e Gestão (MPOG) e aponta vários danos que já existiam na época e que subsidiou o pedido de desocupação do prédio para que fosse realizada uma reforma. Assim, o projeto arquitetônico - projeto básico e especificações técnicas - foi desenvolvido e o edital da obra publicado em dezembro de 2015. A empresa que venceu a concorrência está em fase de mobilização para montagem do canteiro de obras e início dos serviços de demolições necessárias.

Atualmente, uma intervenção planejada relacionada ao conforto térmico e lumínico dos edifícios exige considerar a sua eficiência energética para que fiquem dentro de padrões razoáveis de consumo. Como enfatizado na Lei no 10.295 (BRASIL, 2001a) “o Poder Executivo desenvolverá mecanismos que promovam a eficiência energética nas edificações construídas no país". O Decreto no 4.059 (BRASIL, 2001b) que regulamenta a lei, afirma que o consumo de equipamentos e edifícios devem ser estabelecidos com base em indicadores técnicos e regulamentação específica. Em 2014 o MPOG publicou a Instrução Normativa 02 que obriga as novas edificações federais, ou as que passarem por retrofit - reformas de edificações que afetem a envoltória, sistema elétrico e arcondicionado, a serem projetadas para a obtenção da etiqueta " $A$ " na certificação Procel, que avalia o consumo energético.

\section{Conclusões}

As intervenções realizadas pelos usuários para o uso ao longo do tempo somadas à manutenção precária causaram danos nos elementos e sistemas do edifício. Tal condição afeta a durabilidade dos componentes aplicados e a vida útil do edifício. Do ponto de vista da preservação do patrimônio moderno é um desafio adequar os edifícios às necessidades dos usuários, conservar suas características, principalmente pela falta de projetos e documentos que indiquem como os sistemas foram projetados originalmente e o as built com as alterações realizadas. 
O estado de conservação do edifício é precário já que as anomalias identificadas prejudicam o uso e adequação ambiental, além de colocar em risco a saúde e/ou a segurança, podendo motivar acidentes com gravidade, no caso de desprendimento dos vidros ou placas cerâmicas da fachada. Assim, há necessidade de ação imediata dos responsáveis pela conservação do edifício já que as rupturas de vidro e desplacamento de cerâmicas têm ocorrido periodicamente.

Nota-se que as intervenções realizadas pelos usuários foram necessárias para atender às suas novas demandas. No entanto, a falta de um projeto de atualização que vislumbrasse os impactos nos sistemas de forma global, associados às manutenções realizadas apenas de forma corretiva, contribuíram para o atual estado de conservação do edifício, chegando ao ponto de paralisar as atividades por obsolescência e degradação da edificação. Dessa forma, a inspeção predial baseada nas análises visuais permitiu constatar a importância das ações planejada, considerando o edifício de forma integrada.

A adoção de um plano de manutenção preventiva é essencial para o monitoramento dos danos ou mesmo para impedir que estes ocorram e prejudiquem a utilização dos ambientes. Este plano deve ser revisado sempre que as intervenções e atualizações dos sistemas construtivos ocorrerem, de forma a prolongar a vida útil destes, mantendo-se as características do patrimônio moderno.

\section{Referências bibliográficas}

ASSOCIAÇÃO BRASILEIRA DE NORMAS TÉCNICAS. NBR 9077: Saídas de emergência em edifícios. Rio de Janeiro, 1993.

NBR 15575-1: Edificações habitacionais: desempenho - Requisitos gerais. Rio de Janeiro, 2013.

NBR 16747: Inspeção Predial - Diretrizes, conceitos, terminologia e procedimento. Rio de Janeiro, 2020, $20 \mathrm{p}$.

BRASIL-a. Lei no 10.295, de 17 de outubro de 2001. Dispõe sobre a Política Nacional de Conservação e Uso Racional de Energia. Brasília, DF, 2001a. Disponível em: <http://www.planalto.gov.br/ccivil_03/leis/leis_2001//10295.htm >. Acesso em: 11 jan. 2021.

BRASIL-b. Decreto no 4.059, de 19 de dezembro de 2001. Regulamenta a Lei no 10.295, de 17 de outubro de 2001. Dispõe sobre a Política Nacional de Conservação e Uso Racional de Energia, e dá outras providências. Brasília, DF, 2001b. Disponível em: <http:// http://www.planalto.gov.br/ccivil_03/decreto/2001/D4059.htm>. Acesso em: 11 jan. 2021.

BOTTEGA, G. S. S. et al . Análise de manuais de uso, operação e manutenção de edificações residenciais. In: ENCONTRO NACIONAL DE TECNOLOGIA DO AMBIENTE CONSTRUÍDO, 18., 2020, Porto Alegre. Anais... Porto Alegre: ANTAC, 2020.

BRAGA, B. M.; PAIVA, R. A. Intervenção no Palácio da Abolição em Fortaleza: flexibilidade e permanência. In: $11^{\circ}$ SEMINÁRIO NACIONAL DO DOCOMOMO BRASIL. Recife: DOCOMOMO_BR, 2016. p. 1-12.

JOHN, V. M.; SATO, N. M. N. Durabilidade de componentes da construção. Revista Ambiente Construído, Porto Alegre, v. 7, p. 20-57, 2006.

PEREIRA, C.; BRITO, J.; SILVESTRE, J. Global Inspection, Diagnosis and Repair System for Buildings: homogenising the classification of repair techniques. XV International Conference On Durability Of Building Materials And Components. Ebook Of Proceedings, [S.L.], p. 827-834, 2020. CIMNE. http://dx.doi.org/10.23967/dbmc.2020.072.

PEREZ, H.; TAH, J. H. M.; MOSAVI, A. Deep Learning for Detecting Building Defects Using Convolutional Neural Networks. Sensors, [S.L.], v. 19, n. 16, p. 1-22, 15 ago. 2019. MDPI AG. http://dx.doi.org/10.3390/s19163556. 